\title{
Analisis Risiko Karakteristik, Sosial Ekonomi, Perilaku dan Kondisi Lingkungan Rumah terhadap Kejadian Malaria
}

\author{
The Risk Analysis of Characteristic, Socioeconomics, Behavioral, and Home \\ Environment Conditions toward Malaria Incidence
}

\author{
Susy Sriwahyuni Sukiswo*, Rinidar**, Sugito**
}

\begin{abstract}
*Jurusan Epidemiologi Fakultas Kesehatan Masyarakat Universitas Teuku Umar, **Prodi Magister Kesehatan Masyarakat Veteriner Universitas Syiah Kuala Unsyiah
\end{abstract}

\begin{abstract}
Abstrak
Malaria merupakan penyakit menular yang menjadi perhatian global. Kecamatan Arongan Lambalek merupakan daerah rawan malaria di Kabupaten Aceh Barat dengan kategori Medium Incidence Area dengan nilai Annual Parasite Incidence (API) 3,67 per 1000 penduduk masih di atas target API Nasional pada fase eliminasi API kurang dari 1 per 1000 penduduk tahun 2013. Penelitian ini bertujuan menganalisis karakteristik, sosial ekonomi, perilaku, dan kondisi lingkungan rumah yang berpengaruh terhadap kejadian malaria di Kecamatan Arongan Lambalek, Kabupaten Aceh Barat. Jenis penelitian ini adalah observasional analitik dengan pendekatan kasus kontrol dengan metode penarikan sampel yaitu purposive sampling. Jumlah sampel dalam penelitian ini terdiri 33 kasus dan 33 kontrol, kelompok kasus adalah orang yang dinyatakan positif malaria sedangkan kelompok kontrol orang yang dinyatakan negatif berdasarkan pemeriksaan mikroskopis/rapid diagnostic test tahun 2014. Analisis statistik yang digunakan analisis univariat, bivariat (kai kuadrat), dan multivariat (regresi logistik). Hasil analisis bivariat diketahui ada lima variabel yang berpengaruh, yaitu pekerjaan $(p=0,000, O R=0,05)$, pengetahuan $(p=$ $0,000 ; \mathrm{OR}=17,5)$, sikap $(p=0,001 ; \mathrm{OR}=7,43)$, tindakan $(p=0,000 ; \mathrm{OR}$ $=9,8)$, dan lingkungan $(p=0,000 ; O R=9,0)$. Berdasarkan hasil analisis multivariat, pengetahuan adalah determinan yang paling berpengaruh $(p=$ 0,006; OR $=12,783, \mathrm{Cl} 95 \%=2,045-79,893$ ). Penyuluhan yang intensif mengenai malaria perlu dilakukan untuk lebih menambah pengetahuan dan informasi masyarakat.
\end{abstract}

Kata kunci: Karakteristik, lingkungan, malaria, perilaku, sosial ekonomi

\section{Abstract}

Malaria is an infectious disease of global concern. The Subdistrict of Arongan Lambalek in West Aceh which belongs to the Medium Incidence Area category was a malaria endemic area with Annual Parasite Incidence (API) 3,67 at 1000 population in 2013. The API was higher than national API on elimination phage less than 1 at 1000 population. The objective of this research was to analyze the characteristic, socioeconomic, behavioral, home environment conditions to determine of malaria incidence in Arongan Lambalek Subdistrict, of West Aceh District. This research was analytic observational case control approach with purposive sampling method. The number of samples in this study comprised 33 cases and 33 controls, the cases are people who tested positive for malaria, while the control group of people who tested negative by examination microscopic/rapid diagnostic test in 2014. The statistical analysis used univariate, bivariate (chi-square), and multivariate (logistic regression). The results of the bivariate analysis are five variables known to affect malaria, they are job $(p=0.000, O R=$ $0.05)$, knowledge $(p=0.000 ; O R=17.5)$, attitude $(p=0.001 ; O R=7.43)$, action $(p=0.000 ; O R=9.8)$, and the environment $(p=0.000 ; O R=9.0)$. Based on the results of the multivariate analysis (logistic regression) knowledge is the most dominan determinan $(p=0.006$; OR $=12.783,95 \% \mathrm{Cl}=$ 2.045 to 79.893$)$. Intensive counseling regarding malaria is needed, to make people know more knowledge and information about malaria.

Keywords: Characteristic, environment, malaria, behaviour, socioeconomic

\section{Pendahuluan}

Malaria adalah penyebab kematian nomor lima dari penyakit infeksi di dunia setelah infeksi pernapasan, HIV/AIDS, diare, dan tuberkulosis. Menurut World Health Organization, terdapat 3,3 milyar penduduk tinggal di daerah yang berisiko transmisi malaria. Malaria menyerang sedikitnya 350-500 juta orang setiap tahun dan menyebabkan kematian sekitar 1 juta pertahun. ${ }^{1}$

Kasus malaria di Indonesia masih tinggi, sebesar

Korespondensi: Susy Sriwahyuni Sukiswo, Jurusan Epidemiologi FKM Universitas Teuku Umar. Jl. Alue Peunyareng Aceh Barat, No.Telp: 06557023552,e-mail: susysriwahyuni84@gmail.com 
417.819 kasus positif pada tahun 2012. Provinsi Aceh memiliki 23 kabupaten/kota yang umumnya daerah endemik malaria, dengan nilai annual parasite incidence (API) mencapai $0,44 \%$ pada tahun 2013. Sementara, API Kabupaten Aceh Barat tahun 2013 adalah 0,92\%, dengan jumlah penderita malaria positif sebanyak 175 kasus. Kecamatan Arongan Lambalek merupakan kecamatan yang endemis malaria dengan kategori medium incidence area yang berada di kabupaten Aceh Barat dengan nilai API 3,67 per 1000 penduduk yang menduduki peringkat kedua dari 5 kecamatan endemis tahun 2013.2

Selama bertahun-tahun, kasus malaria tetap bertahan tinggi tanpa diikuti oleh peningkatan upaya pencegahan dan pengendalian. Banyak interpretasi yang diberikan terhadap fakta empiris tersebut meliputi resistensi obat antimalaria, perubahan lingkungan, dan perilaku yang tidak positif. ${ }^{3}$ Masalah malaria menjadi semakin sulit untuk diatasi dan diperkirakan akan menjadi hambatan bagi keberhasilan pembangunan kesehatan. Kerugian semakin terasa bila kelompok usia produktif yang terkena, mengingat mereka adalah tenaga pembangunan utama. Kerugian ditimbulkan akibat malaria dapat mencapai 11\% sampai dengan 49\% dari Pendapatan Asli Daerah dan akan menyebabkan gangguan kesehatan ibu dan anak, inteligensia, produktivitas angkatan kerja, serta merugikan kegiatan pariwisata. ${ }^{4}$

Berdasarkan hasil pengamatan awal, kasus malaria di Kecamatan Arongan Lambalek tinggi karena kasus impor dari Kecamatan Woyla Kabupaten Aceh Barat. Kasus malaria ini meningkat ketika penduduk yang bekerja sebagai penambang emas di Kecamatan Woyla kembali ke Kecamatan Arongan Lambalek dalam keadaan telah terinfeksi malaria. Hal ini memberikan kontribusi terjadinya penularan malaria dari vektor malaria kepada manusia yang sehat akan lebih tinggi. Berbagai kegiatan manusia seperti pembuatan bendungan, pembuatan jalan, pertambangan, dan pembangunan pemukiman baru sering mengakibatkan perubahan lingkungan yang menguntungkan penularan malaria. ${ }^{5}$ Kondisi sosial ekonomi penduduk Kecamatan Arongan Lambalek yang sebagian besar bekerja sebagai penambang emas dan didukung dengan keadaan geografis yang masih banyak dikelilingi oleh rawa-rawa, hutan, dan sungai. Penelitian ini bertujuan untuk menganalisis karakteristik, sosial ekonomi, perilaku masyarakat, dan kondisi lingkungan rumah yang berpengaruh terhadap kejadian malaria di Kecamatan Arongan Lambalek Kabupaten Aceh Barat.

\section{Metode}

Jenis penelitian yang digunakan adalah penelitian observasional analitik menggunakan desain kasus kontrol atau studi retrospektif. Lokasi penelitian dilaksanakan di Puskesmas Drien Rampak Kecamatan Arongan Lambalek Kabupaten Aceh Barat. Waktu penelitian di- mulai dari 5 Januari sampai 31 Oktober 2014. Populasi penelitian ini adalah semua orang yang sediaan darahnya ditemukan Plasmodium berdasarkan hasil pemeriksaan mikroskopis/rapid diagnostic test (RDT) di Puskesmas Drien Rampak Kecamatan Arongan Lambalek dari bulan Januari sampai Agustus 2014. Sampel penelitian diambil melalui buku catatan puskesmas yang tercatat sebagai malaria positif. Besar sampel minimal yang dibutuhkan adalah 29 kasus dan 29 kontrol. Penelitian ini menggunakan seluruh penderita malaria dari bulan Januari sampai Agustus tahun 2014 sebanyak 33 kasus dan 33 kontrol, dengan perbandingan 1:1 yang memenuhi kriteria inklusi dan eksklusi dengan metode purposive sampling. Kriteria inklusi subyek penelitian untuk kelompok kasus adalah responden yang berumur $\geq 15$ tahun, bersedia berpartisipasi dalam penelitian, bertempat tinggal di Kecamatan Arongan Lambalek, dan tercatat sebagai malaria positif berdasarkan hasil pemeriksaan mikroskopis/RDT di Puskesmas Drien Rampak Kecamatan Arongan Lambalek, sedangkan pada kelompok kontrol yaitu bertempat tinggal di Kecamatan Arongan Lambalek, memiliki jenis kelamin dan usia yang sama dengan kelompok kasus dan dinyatakan negatif malaria. Kriteria ekslusi meliputi pengunjung puskesmas yang berusia $<15$ tahun dan tidak bertempat tinggal di Kecamatan Arongan Lambalek. Sumber data berasal dari data primer (kuesioner) dan data sekunder (Laporan Puskesmas dan Dinas Aceh Barat).

Alur penelitian ini terdiri dari dua tahapan. Tahap pertama yaitu tahap persiapan yang meliputi survei kasus di Puskesmas Drien Rampak dari bulan Januari sampai Februari 2014, pengurusan izin penelitian, serta melakukan uji validitas dan realibilitas kuisioner pada 20 responden. Tahap kedua adalah tahap pelaksanaan meliputi perolehan data primer dan data sekunder, setelah data terkumpul selanjutnya dilakukan pengolahan dan analisis data.

Teknik pengumpulan data melalui wawancara, observasi dan survei dokumen. Variabel independen dalam penelitian ini adalah karakteristik, sosial ekonomi, perilaku, dan kondisi lingkungan rumah. Teknik pengukuran variabel independen menggunakan skala likert. ${ }^{6}$

Prosedur analisis data dilakukan dalam tiga tahap, yaitu analisis univariat dilakukan untuk melihat distribusi frekuensi kejadian malaria, analisis bivariat dilakukan dengan uji statistik kai kuadrat pada tingkat kepercayaan $95 \%$ dan nilai $\mathrm{p}<0,05$, dan analisis multivariat dilakukan dengan uji statistik regresi logistik yang terdiri dari tiga tahap. Terdapat berbagai tahap uji regresi logistik, yaitu tahap pertama uji interaksi yang bertujuan mengeluarkan variabel nilai $\mathrm{p}>0,05$, kedua uji confounding pertama dengan melihat perubahan nilai OR crude dan OR adjusted $<10 \%$, kemudian dilakukan pemilihan kandidat model regresi logistik dengan memasukkan semua 
variabel independen yang memenuhi syarat ke dalam model.

Variabel yang tidak signifikan dikeluarkan secara bertahap dimulai dari variabel yang mempunyai nilai $\mathrm{p}$ terbesar sehingga variabel-variabel tersebut ditetapkan sebagai bentuk model (fit model) dengan mempertimbangkan model terbaik dari dua penilaian yaitu signifikan ratio Log likelihood $(\mathrm{p}<0,05){ }^{7}$

\section{Hasil}

Dari empat variabel, diperoleh persentase tertinggi pada kelompok kasus terletak pada subvariabel responden yang bekerja sebesar 93,9\%, pengetahuan kurang baik dan tindakan kurang baik masing-masing sebesar $84,8 \%$, serta kondisi lingkungan yang buruk sebesar $81,8 \%$ (Tabel 1).

Hasil penelitian pada Tabel 1, variabel karakteristik subvariabel usia menunjukkan tidak ada hubungan bermakna antara usia dengan kejadian malaria karena proporsi responden yang berusia muda $(51,5 \%)$ tidak terlalu berbeda dengan responden berusia tua $(48,5 \%)$ pada kelompok kasus dengan nilai $p=0,455$. Sedangkan, pada subvariabel pendidikan menunjukkan tidak ada hubungan bermakna antara pendidikan dengan kejadian malaria karena proporsi responden yang berpendidikan menengah lebih banyak pada kelompok kasus $(60,6 \%)$ dibanding pendidikan rendah $(27,3 \%)$ dan tinggi $(12,1)$, dengan nilai $p=0,611$. Pada subvariabel pekerjaan, yang bekerja $(93,9 \%)$ lebih tinggi daripada yang tidak bekerja $(6,1 \%)$. Kelompok kasus menunjukkan ada hubungan pekerjaan dengan malaria $(\mathrm{p}=0,000 ; \mathrm{OR}=0,048)$.

Hasil penelitian sosial ekonomi menunjukkan tidak ada hubungan lokasi tempat tinggal dengan kejadian malaria $(\mathrm{p}=0,455)$ karena proporsi lokasi tempat tinggal baik pada kelompok kasus $(51,5 \%)$ tidak terlalu berbeda dengan kelompok kontrol $(63,6 \%)$. Pada akses pelayanan kesehatan, hasil membuktikan tidak ada hubungan dengan kejadian malaria $(\mathrm{p}=0,782)$, karena proporsi akses pelayanan kesehatan mendukung $(69,7 \%)$ tidak terlalu berbeda dengan akses yang tidak mendukung $(30,3 \%)$ pada kelompok kasus. Hasil menunjukkan tidak ada hubungan penghasilan dengan kejadian malaria ( $p=0,128$ ), karena proporsi penghasilan tinggi lebih tinggi pada kelompok kasus $(48,5 \%)$ dibandingkan kelompok kontrol $(27,3 \%)$.

Variabel perilaku untuk pengetahuan hasil membuktikan ada hubungan dengan kejadian malaria $(\mathrm{p}=0,000$; $\mathrm{OR}=7,50$ ), proporsi pengetahuan kurang lebih banyak pada kelompok kasus $(84,8 \%)$ dibandingkan kelompok kontrol $(24,2 \%)$. Pada subvariabel sikap juga ada hubungan dengan kejadian malaria ( $\mathrm{p}=0,001$; $\mathrm{OR}=7,429$ ), proporsi sikap negatif lebih tinggi pada kelompok kasus $(78,8 \%)$ dibandingkan kelompok kontrol (33,3\%). Hasil membuktikan bahwa tindakan ada hubungan dengan ke-

Tabel 1. Hubungan dan Besar Risiko Variabel Independen terhadap Kejadian Malaria

\begin{tabular}{|c|c|c|c|c|c|c|c|c|}
\hline \multirow{2}{*}{ Variabel } & \multirow{2}{*}{ Kategori } & \multicolumn{2}{|c|}{ Kasus } & \multicolumn{2}{|c|}{ Kontrol } & \multirow{2}{*}{ Nilai p } & \multirow{2}{*}{ OR } & \multirow{2}{*}{ CI 95\% } \\
\hline & & $\mathbf{N}$ & $\%$ & $\mathbf{N}$ & $\%$ & & & \\
\hline \multicolumn{9}{|l|}{ Karakteristik : } \\
\hline \multirow[t]{2}{*}{ Usia } & Muda & 17 & 51,5 & 21 & 63,6 & 0,455 & 0,607 & $0,227-1,625$ \\
\hline & Tua & 16 & 48,5 & 12 & 36,4 & & & \\
\hline \multirow[t]{2}{*}{ Pendidikan } & Rendah & 9 & 27,3 & 12 & 36,4 & 0,611 & - & - \\
\hline & Tinggi & 4 & 12,1 & 5 & 15,2 & & & \\
\hline \multirow[t]{2}{*}{ Pekerjaan } & Tidak bekerja & 2 & 6,1 & 19 & 57,6 & 0,000 & 0,048 & $0,010-0,233$ \\
\hline & Bekerja & 31 & 93,9 & 14 & 42,4 & & & \\
\hline \multicolumn{9}{|l|}{ Sosial Ekonomi : } \\
\hline \multirow[t]{2}{*}{ Lokasi tempat tinggal } & Kurang baik & 16 & 48,5 & 12 & 36,4 & 0,455 & 1,647 & $0,615-4,408$ \\
\hline & Baik & 17 & 51,5 & 21 & 63,6 & & & \\
\hline Akses Pelayanan Kesehatan & Tidak mendukung & 10 & 30,3 & 8 & 24,2 & 0,782 & 1,359 & $0,457-4,035$ \\
\hline \multirow[t]{2}{*}{ Penghasilan } & Rendah & 17 & 51,5 & 24 & 72,7 & 0,128 & 0,398 & $0,143-1,112$ \\
\hline & Tinggi & 16 & 48,5 & 9 & 27,3 & & & \\
\hline \multicolumn{9}{|l|}{ Perilaku Masyarakat: } \\
\hline \multirow[t]{2}{*}{ Pengetahuan } & Kurang baik & 28 & 84,8 & 8 & 24,2 & 0,000 & 17,50 & $5,061-60,52$ \\
\hline & Baik & 5 & 15,2 & 25 & 75,8 & & & \\
\hline \multirow[t]{2}{*}{ Sikap } & Negatif & 26 & 78,8 & 11 & 33,3 & 0,001 & 7,429 & $2,461-22,42$ \\
\hline & Positif & 7 & 21,2 & 22 & 66,7 & & & \\
\hline \multirow[t]{2}{*}{ Tindakan } & Kurang baik & 28 & 84,8 & 12 & 36,4 & 0,000 & 9,800 & $2,991-32,11$ \\
\hline & Baik & 5 & 15,2 & 21 & 63,6 & & & \\
\hline \multirow[t]{2}{*}{ Lingkungan Rumah } & Buruk & 27 & 81,8 & 11 & 33,3 & 0,000 & 9,000 & $2,870-28,22$ \\
\hline & Baik & 6 & 18,2 & 22 & 66,7 & & & \\
\hline
\end{tabular}


Tabel 2. Hasil Analisis Multivariat Regresi Logistik Antarvariabel Kandidat Kejadian Malaria (Nilai $\mathrm{p}<0,05)$

\begin{tabular}{|c|c|c|c|c|}
\hline Variabel & B & Nilai $p$ & OR & 95\% CI \\
\hline \multicolumn{5}{|l|}{ Tahap 1: } \\
\hline Pekerjaan & $-2,720$ & 0,032 & 0,066 & $0,005-0,797$ \\
\hline Penghasilan & 0,509 & 0,637 & 1,664 & $0,201-13,775$ \\
\hline Pengetahuan & 2,275 & 0,023 & 9,731 & $1,368-69,249$ \\
\hline Sikap & 1,380 & 0,136 & 3,977 & $0,648-24,420$ \\
\hline Tindakan & 2,260 & 0,029 & 9,579 & $1,256-73,058$ \\
\hline Lingkungan & 2,371 & 0,021 & 10,708 & $1,436-79,848$ \\
\hline Konstanta & $-4,233$ & 0,003 & 0,015 & \\
\hline \multicolumn{5}{|l|}{ Tahap 2: } \\
\hline Pekerjaan & $-2,493$ & 0,034 & 0,083 & $0,008-0,832$ \\
\hline Pengetahuan & 2,207 & 0,024 & 9,091 & $1,334-61,969$ \\
\hline Sikap & 1,387 & 0,135 & 4,004 & $0,648-24,723$ \\
\hline Tindakan & 2,192 & 0,031 & 8,957 & $1,215-66,008$ \\
\hline Lingkungan & 2,539 & 0,010 & 12,671 & $1,829-87,792$ \\
\hline Konstanta & $-4,020$ & 0,003 & 0,018 & \\
\hline \multicolumn{5}{|l|}{ Tahap 3: } \\
\hline Pekerjaan & $-2,449$ & 0,027 & 0,086 & $0,010-0,755$ \\
\hline Pengetahuan & 2,548 & 0,006 & 12,783 & $2,045-79,893$ \\
\hline Tindakan & 2,281 & 0,018 & 9,785 & $1,476-64,870$ \\
\hline Lingkungan & 2,217 & 0,014 & 9,182 & $1,563-53,922$ \\
\hline Konstanta & $-3,375$ & 0,003 & 0,034 & \\
\hline
\end{tabular}

Ket : -2 Log-Likelihood $=37,006 ; G=54,489 ;$ nilai $p=0,000$

Tabel 3. Hasil Akhir Uji Regresi Logistik Variabel Paling Berpengaruh terhadap Kejadian Malaria

\begin{tabular}{|c|c|c|c|c|}
\hline Variabel & B & Nilai p & OR & $95 \% \mathrm{CI}$ \\
\hline Pekerjaan & $-2,449$ & 0,027 & 0,086 & $0,010-0,755$ \\
\hline Pengetahuan & 2,548 & 0,006 & 12,783 & $2,045-79,893$ \\
\hline Tindakan & 2,281 & 0,018 & 9,785 & $1,476-64,870$ \\
\hline Lingkungan & 2,217 & 0,014 & 9,182 & $1,563-53,922$ \\
\hline Konstanta & $-3,375$ & 0,003 & 0,034 & \\
\hline
\end{tabular}

jadian malaria ( $\mathrm{p}=0,000$; $\mathrm{OR}=9,800)$, yang proporsi tindakan tidak baik lebih tinggi pada kelompok kasus (84,8\%) dibandingkan kelompok kontrol (36,4\%).

Pada variabel kondisi lingkungan rumah menunjukkan ada hubungan dengan kejadian malaria $(\mathrm{p}=$ 0,000; OR $=9,000$ ), proporsi kondisi lingkungan rumah buruk lebih tinggi pada kelompok kasus $(81,85 \%)$ dibandingkan kelompok kontrol (33,3\%).

Pada Tabel 2, analisis multivariat dilakukan berdasarkan hasil uji kai kuadrat yang memenuhi syarat $(\mathrm{p}<0,25)$. Untuk tahap pertama uji interaksi, dilakukan mengeluarkan variabel penghasilan $(p=0,637)$ dan sikap $(p=0,135)$. Dari hasil uji interaksi yang dilakukan, tidak ada interaksi antara variabel satu dengan variabel lain. Uji confounding pertama yaitu penghasilan $(\mathrm{p}=0,637)$, uji confounding kedua pada variabel sikap $(\mathrm{p}=0,135)$, dengan melihat perubahan nilai OR crude dan OR adjusted $<10 \%$, maka variabel tersebut dinyatakan bukan confounding dan harus dikeluarkan dalam model.

Berdasarkan hasil regresi logistik tahap akhir diper- oleh variabel pekerjaan nilai $(\mathrm{p}=0,027$; $\mathrm{OR}=0,086)$, pengetahuan $(\mathrm{p}=0,006$; $\mathrm{OR}=12,783)$, tindakan $(\mathrm{p}=$ $0,018 ;$ OR $=9,785)$, dan lingkungan $(\mathrm{p}=0,014$; $\mathrm{OR}=$ $9,182)$ mempunyai hubungan dengan kejadian malaria di Kecamatan Arongan Lambalek (Tabel 3).

Berdasarkan hasil analisis multivariat diperoleh ada 6 variabel yang menjadi kandidat model $(\mathrm{p}<0,25)$, yaitu penghasilan, pekerjaan, pengetahuan, sikap, tindakan, dan kondisi lingkungan rumah. Model terbaik akan mempertimbangkan dua penilaian yaitu signifikan ratio $\mathrm{Log}$ likelihood $(\mathrm{p}<0,05)$. Pemilihan model dilakukan pada semua variabel independen yang memenuhi syarat dimasukkan dalam model. Variabel yang tidak signifikan dikeluarkan secara bertahap dimulai dari variabel yang mempunyai nilai $\mathrm{p}$ terbesar. Setelah dilakukan uji interaksi dan penilaian confounding di peroleh empat variabel memiliki nilai $\mathrm{p}<0,05$, variabel-variabel tersebut ditetapkan sebagai bentuk model (fit model) yaitu pengetahuan, tindakan, lingkungan dan pekerjaan, dengan Persamaan 1.

Persamaan 1.

$\mathrm{Y}=-3,375+2,548 \mathrm{X}_{1}($ Pengetahuan $)+2,281 \mathrm{X}_{2}($ Tindakan $)+2,217 \mathrm{X}_{3}$ (Lingkungan) - 2,449 $\mathrm{X}_{4}$ (Pekerjaan)

\section{Pembahasan}

Secara umum, semua golongan usia (bayi, balita, ibu hamil, dan usia lanjut) berisiko terhadap infeksi parasit malaria. Perbedaan prevalensi menurut usia berkaitan dengan perbedaan derajat kekebalan terhadap malaria. ${ }^{8}$ Faktor usia pada penelitian ini tidak bermakna karena responden yang diambil dari yang berusia $\geq 15$ tahun, sehingga tidak ada perbedaan kekebalan terhadap infeksi malaria. Bertambah usia membuat kekebalan terhadap malaria semakin meningkat. Penelitian ini sejalan yang dilakukan di daerah perbatasan Kabupaten Trenggalek dan Tulangangung yang menunjukkan tidak ada hubungan antara usia dengan kejadian malaria $(\mathrm{p}=0,235) .{ }^{9}$

Tingkat pendidikan memengaruhi kemampuan seseorang dalam memahami suatu masalah, selanjutnya pemahaman akan membentuk sikap dan dengan pengaruh lingkungan menghasilkan perilaku nyata (tindakan) sebagai suatu reaksi. ${ }^{10}$ Teori tersebut berbeda dengan hasil penelitian di Kecamatan Arongan Lambalek yang menunjukkan kejadian malaria dominan terjadi pada yang berpendidikan Sekolah Menengah Atas (SMA). Berdasarkan hasil pengumpulan data diperoleh bahwa responden yang berpendidikan menengah lebih banyak berpengetahuan yang kurang tentang malaria dengan persentase $(61,1 \%)$ dibandingkan dengan yang berpendidikan rendah $(30,6 \%)$, dan tinggi $(8,3 \%)$. Hal ini diduga erat karena rendahnya kesadaran masyarakat Kecamatan Arongan Lambalek tentang pentingnya upaya pencegahan malaria. Pencarian informasi yang benar 
meliputi penyebab, cara penularan, cara pencegahan, dan pengobatan dini malaria jarang dilakukan. Rendahnya pemahaman dan pengetahuan malaria adalah penyebab perilaku yang salah terhadap malaria. Penelitian ini sejalan yang dilakukan di daerah perbatasan Kabupaten Trenggalek dan Tulangangung yang menunjukkan bahwa tidak ada hubungan pendidikan dengan kejadian malaria $(p=0,444) .{ }^{9}$ Seseorang yang memiliki pengetahuan dan perilaku yang baik akan menghindarkan orang tersebut dari risiko terkena penyakit malaria. ${ }^{10}$

Beberapa jenis pekerjaan merupakan faktor risiko dan memberi peluang untuk kontak dengan nyamuk. Misalnya petani, berkebun, nelayan, dan penambang emas. ${ }^{5}$ Suharjo et al, ${ }^{11}$ menyatakan bahwa tingkat mobilitas penduduk dari segi pekerjaan maupun pendatang dari daerah endemis memengaruhi penularan malaria impor di suatu daerah. Risiko kejadian malaria adalah 0,048 kali lebih besar pada orang yang bekerja dibandingkan dengan orang tidak bekerja, hal ini disebabkan sebagian besar masyarakat Kecamatan Arongan Lambalek bekerja sebagai petani dan penambang emas. Penambangan ini dilakukan di area Gunung Ujeun Kecamatan Woyla dan pekerjanya sebagian besar merupakan penduduk Kecamatan Arongan Lambalek.

Pekerja-pekerja tersebut sering menginap di tempat kerja tanpa memperhatikan kebersihan tempat tinggal dan tanpa melindungi diri dari malaria sehingga memungkinkan terjadinya peningkatan kasus setelah pekerja tersebut kembali ke Kecamatan Arongan Lambalek. Bekerja sebagai petani juga harus berada di hutan sampai sore sehingga akan memberikan kontribusi positif terhadap transmisi penularan malaria. Hasil penelitian sesuai dengan penelitian yang dilakukan di Kecamatan Mandor Kabupaten Landak Propinsi Kalimantan Barat yang menunjukkan ada hubungan yang signifikan antara pekerjaan dengan kejadian malaria (nilai $\mathrm{p}=0,001$; $\mathrm{OR}=3,4) \cdot{ }^{12}$

Berdasarkan persamaan yang diperoleh, pekerjaan berkontribusi negatif. Hal ini menunjukkan bahwa semakin banyak yang bekerja di luar tanpa ada usaha perlindungan diri maka semakin tinggi angka kejadian malaria di Kecamatan Arongan Lambalek. Sebagian besar penduduk bekerja sebagai petani dan penambang emas yang merupakan tempat potensial perindukan nyamuk malaria.

Lokasi tempat tinggal penderita malaria di Kecamatan Arongan Lambalek jauh dari saluran irigasi yang merupakan tempat perkembangbiakan dan peristirahatan nyamuk malaria. Akses pelayanan kesehatan di Kecamatan Arongan Lambalek sudah memadai untuk menjangkau sarana pelayanan kesehatan, hanya membutuhkan waktu kira-kira 15 menit untuk tiba di puskesmas dengan jarak tempuh 1-5 km. Semakin jauh jarak tempuh ke sarana pelayanan kesehatan maka semakin besar risiko menderita penyakit malaria. ${ }^{13}$ Kelle et al, ${ }^{14}$ menyatakan akses pelayanan kesehatan mudah dijangkau penduduk Desa Manglusi jika menggunakan kendaraan roda dua maupun empat. Penelitian ini sejalan dengan penelitian yang dilakukan Sari et al, 15 di Provinsi Bengkulu yang menunjukkan bahwa tidak ada hubungan antara jarak tempuh pelayanan kesehatan dengan kejadian malaria.

Mortalitas dan morbiditas ditentukan juga oleh taraf sosial ekonomi seseorang. ${ }^{4}$ Walaupun penderita malaria Kecamatan Arongan Lambalek mempunyai penghasilan yang lebih tinggi, angka kejadian malaria tetap tinggi. Hal ini menunjukkan bahwa masyarakat belum menggunakan sebagian pendapatannya untuk mengupayakan pencegahan kontak dengan nyamuk, seperti membeli kawat kasa atau obat anti nyamuk. Status ekonomi akan memengaruhi kejadian malaria tetapi tidak mendasari perubahan perilaku kesehatan jika tidak diikuti dengan pelaksanaan tindakan pencegahan. ${ }^{10}$

Pada subvariabel pengetahuan menunjukkan ada hubungan antara pengetahuan dengan kejadian malaria. Subjek yang berpengetahuan kurang memiliki risiko 17,5 kali lebih besar dibandingkan dengan yang berpengetahuan baik. Penelitian lain dilakukan di wilayah kerja Puskesmas Kasimbar Kabupaten Parigi Moutong Sulawesi Tengah, menunjukkan pengetahuan mempunyai hubungan bermakna dengan kejadian malaria ( $\mathrm{p}=$ 0,037 ) dengan risiko 3,05 kali lebih besar terkena malaria pada orang yang berpengetahuan rendah dibandingkan orang yang berpengetahuan tinggi. ${ }^{16}$ Perilaku seseorang dipengaruhi oleh pengetahuan. Kurangnya pengetahuan berdampak terhadap kesadaran masyarakat yang rendah terhadap pencegahan malaria, misalnya penyehatan lingkungan. ${ }^{10}$ Berdasarkan hasil wawancara diperoleh sebagian besar masyarakat Kecamatan Arongan Lambalek tidak mengetahui dengan benar penyebab, cara penularan, gejala, bahaya malaria, pengobatan, pencegahan, dan penularan malaria.

Hasil model akhir diperoleh satu variabel yang paling berpengaruh terhadap kejadian malaria dengan melihat nilai OR yang terbesar yaitu variabel pengetahuan (nilai $\mathrm{p}=0,006$ ) diperoleh OR sebesar 12,783 yang artinya bahwa orang yang mempunyai pengetahuan kurang berisiko sebesar 12,783 kali lebih besar terkena malaria daripada orang yang berpengetahuan baik. Penelitian ini sejalan dengan penelitian Serumpaet et $a l,{ }^{17}$ menyatakan bahwa pengetahuan merupakan faktor intrinsik yang berpengaruh terhadap kejadian malaria.

Terdapat hubungan bermakna antara sikap dengan kejadian malaria di Kecamatan Arongan Lambalek dengan risiko 7,4 kali lebih besar pada orang yang bersikap negatif dibandingkan dengan orang yang bersikap positif. Sejalan dengan penelitian yang dilakukan di Kabupaten Parigi Moutong Sulawesi Tengah yaitu sikap berpengaruh 
terhadap kejadian malaria $(\mathrm{p}=0,04, \mathrm{OR}=8,07) \cdot{ }^{16}$ Didukung juga dengan penelitian yang dilakukan di Kecamatan Rowokele Kabupaten Kebumen yang menunjukkan dari 269 sampel, 54,3\% mempunyai sikap negatif terhadap pengendalian malaria. ${ }^{18}$ Munculnya sikap kurang mendukung terhadap usaha pencegahan malaria di kecamatan Arongan lambalek meliputi sikap penggunaan kelambu insektisida, anti nyamuk oles, memakai baju lengan panjang saat keluar malam, dan usaha perlindungan dari gigitan nyamuk di lokasi kerja seperti pertambangan atau persawahan. Sikap yang negatif cenderung membawa masyarakat untuk bertindak lebih buruk dalam mencegah terjadinya penularan penyakit termasuk malaria. ${ }^{10}$

Hasil statistik menunjukkan ada hubungan tindakan dengan kejadian malaria di Kecamatan Arongan Lambalek. Orang yang memiliki tindakan kurang baik mempunyai risiko terjangkit malaria 9,8 kali lebih besar dibandingkan orang yang memiliki tindakan baik. Hal ini sesuai dengan penelitian yang dilakukan di Kabupaten Parigi Moutong Sulawesi Tengah bahwa tindakan mempunyai hubungan bermakna dengan kejadian malaria ( $\mathrm{p}$ $=0,02 ;$ OR $=10) \cdot{ }^{16}$ Dari hasil pengumpulan data, masyarakat Kecamatan Arongan Lambalek tidak mencerminkan perilaku yang mendukung pengendalian dan pencegahan malaria. Misalnya tidak menggunakan kelambu saat tidur malam hari atau saat bermalam di lokasi pekerjaan, tidak langsung berobat ke puskesmas jika terjadi gejala malaria, tidak mengikuti penyuluhan malaria di desa, tidak memasang kawat kawa pada ventilasi rumah, serta tidak mengikuti petunjuk dan aturan minum obat dari dokter saat terinfeksi malaria.

Penelitian yang dilakukan oleh Wogu et al, ${ }^{19}$ pada tahun 2013 di Negeria Delta menunjukkan bahwa terdapat hubungan yang bermakna antara ibu hamil yang positif malaria dengan kebiasaan tidak menggunakan kelambu. Penelitian oleh Bhatt et al, ${ }^{20}$ pada tahun 2012 menyatakan bahwa penggunaan kelambu berinsektisida efektif dalam mengurangi kepadatan nyamuk. Cara lain untuk mengurangi risiko tergigit oleh nyamuk malaria adalah menggunakan obat anti nyamuk. ${ }^{21}$ Tingginya angka kejadian malaria dipengaruhi oleh kebiasaan tidak memakai kelambu, tidak memakai obat nyamuk, dan aktivitas di luar rumah pada malam hari. ${ }^{22}$

Hasil analisis menunjukkan ada hubungan signifikan antara lingkungan dengan kejadian malaria di Kecamatan Arongan Lambalek dengan risiko terjadinya malaria sebesar 9,0 kali lebih besar pada masyarakat yang tinggal di lingkungan buruk dibandingkan dengan masyarakat di lingkungan baik. Hasil penelitian ini sejalan dengan penelitian yang dilakukan di wilayah kerja Puskesmas Sarmi Kota Kabupaten Sarmi yang menunjukkan bahwa lingkungan yang terdapat genangan air dan semak-semak berhubungan dengan kejadian malaria $(p=0,000 ;$ OR $=6,827) .23$ Berdasarkan hasil observasi di lokasi penelitian, diketahui terdapat banyak tempat perkembangbiakan bagi nyamuk malaria. Rumah yang berjarak kurang dari 100 meter dengan kandang ternak akan meningkatkan frekuensi gigitan nyamuk dan penularan malaria. Masih banyaknya hutan di dekat rumah dan keberadaan semak yang rimbun akan mengurangi sinar matahari masuk atau menembus permukaan tanah, sehingga lingkungan disekitarnya akan menjadi teduh dan lembab. Selain itu, adanya genangan air dan saluran pembuangan air limbah (SPAL) yang tidak tertata rapi disekitar rumah juga menjadi risiko. ${ }^{24}$ Tempat perkembangbiakan nyamuk yang potensial adalah genangan air. Banyaknya tempat perkembangbiakan nyamuk seperti hutan, semak, sawah, sungai, irigasi, tambak ikan, dan parit-parit yang tidak terurus, jarak rumah dengan kandang ternak yang terlalu dekat, serta adanya pemeliharaan kandang ternak besar dan kecil, membuat kondisi yang menguntungkan bagi vektor nyamuk malaria untuk berkembang biak dan melakukan transmisi penularan malaria. Ini akan berpengaruh terhadap angka kepadatan jentik. $^{3}$

\section{Kesimpulan}

Variabel pekerjaan, kondisi lingkungan rumah, serta perilaku masyarakat yang meliputi pengetahuan, sikap dan tindakan, menunjukkan hubungan yang bermakna dengan kejadian malaria. Variabel usia, pendidikan, dan tingkat sosial ekonomi tidak menunjukan hubungan yang bermakna dengan malaria. Berdasarkan hasil akhir uji regresi logistik, variabel pengetahuan merupakan variabel yang paling dominan berhubungan dengan kejadian malaria di Kecamatan Arongan Lambalek Kabupaten Aceh Barat, dengan OR $=12,78$ dan probabilitas risiko malaria sebesar $95 \%$.

\section{Saran}

Pemeritah daerah bekerjasama dengan Dinas Kesehatan Aceh Barat untuk meningkatkan penyuluhan dan sosialisasi yang intensif dan terintegrasi dengan baik kepada petugas kesehatan. Petugas kesehatan diharapkan lebih aktif melakukan promosi kesehatan, memberikan pemahaman yang lebih, menekankan pada pengetahuan malaria, sikap yang diambil terhadap malaria, dan tindakan pencegahan yang dilakukan oleh masyarakat dalam pengaplikasiannya. Masyarakat diharapkan lebih memperhatikan lingkungan sekitar yang dapat menjadi tempat potensial malaria. Pekerja-pekerja seperti petani dan penambang emas sebaiknya mampu memproteksi diri dari gigitan nyamuk malaria pada saat berada di lokasi pekerjaan

\section{Daftar Pustaka}

1. CDC [homepage in internet]. Impact of malaria. 2010[cited 2014 Sept 10]. 
Available from: http://www. cdc.gov/ malaria/malaria_ worldwide /impact.html.

2. Dinas Kesehatan Aceh Barat. Laporan bulanan penemuan dan pengobatan malaria bidang pengedalian penyakit dan penyehatan lingkungan. Aceh Barat: Dinas Kesehatan Aceh Barat; 2013.

3. Hayat F, Kurniatillah N. Situasi malaria di Kabupaten Lebak. Kesmas Jurnal Kesmas Nasional. 2009; 3(6): 259-63.

4. Achmadi UF. Manajemen penyakit berbasis wilayah. Jakarta: Universitas Indonesia Press; 2008.

5. Harijanto PN. Epidemiologi, patogenesis, manifestasi klinis, dan penanganan. Jakarta: Penerbit EGC; 2000.

6. Sasroasmoro S, Ismail S. Dasar-dasar metodelogi penelitian klinis. Jakarta: Universitas Indonesia; 2002

7. Sugiono. Statistik untuk penelitian. Bandung: Alfabeta; 2011.

8. Anies. Mewaspadai penyakit lingkungan. Jakarta: PT Elex Media Komputer; 2006.

9. Notobroto HB, Hidajah AC. Faktor risiko penularan malaria di daerah berbatasan. Jurnal Penelitian Media Eksakta. 2009; 8 (2): 143-151.

10. Notoatmodjo S. Ilmu Perilaku Kesehatan. Jakarta: Rineka Cipta; 2010.

11. Suharjo, Mardiana. Pengetahuan Masyarakat tentang Malaria di Kabupaten Seribu. Jurnal Ekologi Kesehatan. 2009; 8 (4): 1077-83.

12. Salim M, Suhartono, Endah N. Faktor-faktor yang berhubungan dengan kejadian malaria di wilayah pertambangan emas tanpa izin (peti) Kecamatan Mandor Kabupaten Landak Propinsi Kalimantan Barat. Jurnal Kesehatan Lingkungan Indonesia. 2012; 11 (2): 160-5.

13. Untari J, Hasanbasri M. Kemana pemilik kartu sehat mencari pertolongan (Analisis Survei Sosial Ekonomi Nasional 2001). Jurnal Manajemen Pelayanan Kesehatan. 2007; 10 (1): 20-5.

14. Kelle Y, Arsin AA, Daud A. Perbedaan malaria pada daerah dataran rendah dengan dataran tinggi di Kabupaten Maluku Tenggara Barat. Jurnal Masyarakat Epidemiologi Indonesia. 2013; 2 (1): 71-5.
15. Sari RM, Ambarita LP, Sitorus H. Akses pelayanan kesehatan dan kejadian malaria di Provinsi Bengkulu. Media Litbangkes. 2013; 23 (4): 158-64.

16. Erlan A, Ningsih, Malonda, dan Puryadi. Perilaku Kesehatan Masyarakat Kaitannya dengan Kejadian Malaria di Wilayah Puskesmas Kasimbar Kabupaten Parigi Moutong Sulawesi Tengah. Jurnal Vektor Penelitian. 2008; 2 (1): 25-30.

17. Serumpaet SM, Tarigan R. Faktor Risiko Kejadian Malaria di Kawasan Ekosistem Leuser Kabupaten Karo Provinsi Sumatera Utara. Jurnal IKM. 2007; 11 (13): 55-63.

18. Irawan A, dan Pujianto A. Pengetahuan sikap dan perilaku masyarakat di daerah kejadian luar biasa Desa Wagirpandan Kecamatan Rowokele Kabupaten Kebumen. Jurnal Vektora. 2011; 4 (2): 65-74.

19. Wogu MN, Nduka FO, Wogu MD. Effectiveness and compliance of long lasting insecticide nets (LLINs) on malaria parasitemia among pregnant women attending antenatal clinics in Port Harcourt, Rivers State. British Journal of Medicine \& Medical Research. 2013; 3(4): 1233-9.

20. Bhatt RM, Sharma SN, Uragayala S, Dash AP, Kamaraju R. Effectiveness and Durability of Interceptor Long-Lasting Insecticidal Nets in a Malaria Endemic Area of Central India. Malaria Journal. 2012;11:189.

21. Rubianti I, Wibowo TA, Solikhah. Faktor-Faktor Resiko Malaria di Wilayah Kerja Puskesmas Paruga Kota Bima Nusa Tenggara Barat. Jurnal Kesehatan Masyarakat. 2009; 3(3): 162-232.

22. Santi, Fitriangga A, Natalia D. Hubungan Faktor Individu dan Lingkungan dengan Kejadian Malaria di Desa Sungai Ayak 3 Kecamatan Belitang Hiling, Kabupaten Sekadau. JKLI. 2014; 4 (1): 265-75.

23. Imbiri J, Suhartono, dan Nujazulli. Analysis of Malaria Risk Factors in Sarmi Municipal Public Health Service Working Area. Jurnal Kesehatan Lingkungan Indonesia. 2012; 11 (2): 130-7.

24. Ahmadi S, Sulistyani, dan Raharjo M. Faktor Risiko Kejadian Malaria Di Desa Lubuk Nipis Kecamatan Tanjung Agung Kabupaten Muara Enim. Jurnal Kesehatan Lingkungan Indonesia. 2008;8 (1): 20-5. 